Department of Social Systems and Management

\author{
Discussion Paper Series
}

No.1263

Employment Protection and Incentives:

Severance Pay vs. Procedural Inconvenience

by

Kyota EGUCHI

July 2010

Tsukuba, Ibaraki 305-8573 JAPAN 


\title{
Employment Protection and Incentives: Severance Pay vs. Procedural Inconvenience*
}

\author{
Kyota Eguchi $^{* *}$ \\ University of Tsukuba \\ Department of Social Systems and Management
}

\author{
June 2010 \\ 2010/06/14
}

\footnotetext{
* An earlier version of this paper was presented at the 2009 Far Eastern and South Asian meeting of the Econometric society at the University of Tokyo and the 2008 annual autumn meeting of the Japanese Economic Association at Kinki University. I am grateful to Ryo Kambayashi, Ryoichi Imai, Masaru Sasaki, Hideshi Itoh, Takashi Shimizu, and the seminar participants at the Search Theory Workshop (STW), the Law and Economics Workshop, Tohoku University, Nihon University, the Contract Theory Workshop (CTW), Nanzan University, and Tokei-kenkyu-kai. This research was partially supported by Grant-in-Aid for Scientific Research from the Japanese Ministry of Education. Naturally, any error if present is entirely mine.

JEL Classification Numbers: J41, K31

** Correspondence: Kyota Eguchi, University of Tsukuba, Department of Social Systems and Management, 1-1-1, Tennou-dai, Tsukuba, Ibaraki 305-8573, Japan.

e-mail: eguchi@sk.tsukuba.ac.jp
} 


\title{
Employment Protection and Incentives: Severance Pay vs. Procedural Inconvenience
}

\begin{abstract}
We consider the effects of employment protection (EP) on worker incentives and the labor market with search friction. EP is categorized into severance pay and procedural inconvenience. Severance pay is merely a transfer from firms to dismissed employees while procedural inconvenience yields a wasteful cost. The difference is crucial to the workers' incentives because severance pay is a benefit for shirking employees. Although it appears to negatively affect the workers' incentives, EP, especially procedural inconvenience, has a positive effect on incentives if procedural inconvenience is not severe.
\end{abstract}

JEL Classification Numbers: J64, J65, K31

Key words: Employment protection, Incentives, Commitment, and Efficiency wage. 


\section{Introduction}

Employment protection (EP) is often assumed to negatively affect workers' incentives. A leading theory, the efficiency wage model, holds that the threat of dismissal is a driving force in workers' incentives. If shirking workers are unlikely to be fired due to EP provisions, EP has a disincentive effect. However, EP can have a positive effect on workers' incentives, for example, to learn firm-specific skills. Although an employee works hard, his/her performance or the state of affairs of his/her firm may be very poor in uncertain situations to maintain the employer-employee relationship. If workers who made efforts to learn firm-specific skills are easily fired because of bad business conditions, they realize that they cannot recover the cost of their efforts, and they become unwilling to master firm-specific skills. Because a firm's decision on the dismissal of an employee tends to be based on ex post optimization, credible job security should be provided in such conditions. If EP deters a firm from firing employees, it serves a significant function as a commitment device for job security. This is a commitment effect of procedural inconvenience.

EP can have a negative (disincentive) and a positive (commitment) effect, and therefore should be designed appropriately. The objective of this paper is to consider the effects of EP on the incentives of workers and labor markets with search friction. In this study, we apply the efficiency wage model with the standard matching technology of the Mortensen-Pissarides type and consider the situations in which the commitment effect overrides the disincentive effect.

In this paper, EP incorporates the firm's "firing cost" into the model, and the firing costs are categorized into severance pay (SP) and procedural inconvenience (PI). Although both increase the cost of firing for a firm, SP is merely the transfer of money from a firm to a fired employee, while PI-for example, providing sufficient advance notice or negotiations with a union-leads to a dead weight loss. Note that SP is a benefit for a shirking employee and may damage workers' incentives, in contrast to PI, which provides no benefit to a fired employee. PI, therefore, has a less negative effect on workers' incentives than does SP. Although PI generates dead weight loss, this is an advantage of PI in regard to workers' incentives.

Because numerous studies on EP have provided ambiguous results, our result is not theoretically clear, and hence we used a computer simulation to analyze its effects. According to our simulation, [1] an increase in SP has a negative effect on employees' incentives, thus increasing the cost of retaining an employee. This causes firms to exit the market, resulting in reduced market tightness. As a result, fired workers face the 
difficulty of finding a new job and will remain in the labor market for a long time. Therefore, the unemployment rate tends to increase with an increase in SP. This negative effect of SP is apparent when SP is comparatively low or high. In contrast, the unemployment rate decreases with an increase in SP in the middle range of SP. [2] PI does not provide a sufficient impact when SP is low or high. However, when SP is in the middle range, PI intensifies the commitment effect and encourages workers to work hard. A firm can provide credible job security to an employee through PI and lower wages in exchange for high job security, thus reducing the cost of retaining an employee. PI boosts market tightness and reduces the unemployment rate, but severe PI has a negative effect on the economy.

The result of numerical illustration indicates that a sweeping relaxation in the provisions of EP as well as a very severe EP reduce employees' incentives. Appropriately designed EP improves incentives of employees, and PI plays a more crucial role than SP. PI may logically seem to be less beneficial than SP because SP is a lump-sum transfer while PI generates a wasteful cost. PI, however, is more effective than SP from the viewpoint of employee incentives. It is a crucial message of this paper that EP, especially PI, has a positive effect on employee incentives. This result is consistent with those in studies that accept the positive effect of the firing tax without explicit concern about employee incentives, such as Ljungqvist and Sargent (1998) (2007), Rogerson and Schindler (2002), Pissarides (2001), and Blanchard and Tirole (2008).

Punishment schemes for shirking employees are critical with regard to their incentives. In the context of EP, one crucial issue is whether shirking employees are eligible for SP. Dismissals are therefore categorized into two types of cases that the courts can identify: in the case of redundancy, when firms fire workers due to bad financial health, the workers are eligible; in the case where disciplinary action is taken and workers are fired on the grounds of poor performance or unprofessional conduct, they are not eligible. Naturally, when EP provides benefits only for diligent employees, it is unlikely to cause a negative effect on workers' incentives.

Our purpose, however, is to consider a situation in which the court cannot distinguish between diligent and shirking workers, and any fired employee receives SP. In this situation, EP would be expected to be the cause of employee moral hazard; however, we attempt to show that EP generates a positive impact on employee incentives and the economy through the commitment effect.

There are some studies on EP's effect on worker incentives. Fella (2000) considers the difference between SP and PI by applying the Shapiro and Stiglitz (1984) 
efficiency wage model and presents an insightful result. In the Fella (2000) model, the monitoring technology is the driving force in worker incentives because shirking employees are caught and fired without receiving SP. The monitoring technology avoids the negative effect of SP on worker incentives because SP is unlikely to negatively affect employee incentives since it is unlikely to be granted to shirking employees when the court can distinguish between the behaviors of employees. A firm can thus lower wages in exchange for SP, especially during downturns, which in turn lessens the effect of reducing the employment level during prosperous times. Therefore, it is shown that SP generates a positive effect on the economy, and that if the firing cost is mainly composed of SP, then welfare improves with an increase in SP.

Galdon-Sanchez and Guell (2003) focus on the situation in which the court is unable to distinguish between the cases of redundancy and disciplinary action. In their model, firms allege that workers have been fired for disciplinary reasons even if the opposite is true, so the fired workers do not receive SP because of the firms' moral hazards. In the situation where firms' moral hazard regarding firings is pervasive, some regulations that inhibit firms from firing employees easily are likely to provide positive effects on the economy.

In this paper, we consider a similar situation in which the courts make no distinction between cases of redundancy and disciplinary dismissal, but focus on employee moral hazard. Firms have to pay SP to all fired employees, including shirking employees. In our model, in which monitoring technology is not available, EP seems to cause serious damage. However, it will be shown that EP, especially PI, improves the economy.

This paper is organized as follows. Section 2 presents a Mortensen-Pissarides matching model with an incentive problem and considers the effects of SP and PI as EP categories. We also conduct a computer simulation to investigate the effects of SP and PI in Section 3. Finally, Section 4 presents the conclusions.

\section{The Model}

\section{Employment contract}

A firm as a job vacancy is randomly matched to an unemployed worker in the labor market. After matching, the employed worker is required to make an effort to achieve high productivity, and the effort cost $c$ is borne by the employee. The productivity $p$ of an employee who made an effort is stochastically determined as 
$p \in[0, \bar{p}]$. The density and distribution functions are denoted as $\phi(p)$ and $\Phi(p)$, respectively. If an employee is shirking, the density and distribution functions are denoted by $\phi^{S}(p)$ and $\Phi^{S}(p)$, respectively. The effort cost of a shirking employee is zero. It is assumed that the first-order stochastic dominance holds: $\Phi(p) \leq \Phi^{S}(p)$ for $p \in[0, \bar{p}]$, with strict inequality for a set of values of $p$ with possible probability.

A wage is specified when a firm is matched to a worker. The wage is not conditional on the worker's behavior or his/her productivity $p$, and it is not flexible after the wage is specified. This setting is identical to the Shapiro and Stiglitz (1984) efficiency wage model.

The chronology of the actions of a worker and a firm is as follows:

[1] When a firm is matched to a worker in the labor market, a wage $w$ is specified.

[2] The worker chooses whether or not to make an effort. If he/she makes an effort, he/she bears the effort cost $c$.

[3] If the worker makes an effort, his/her productivity $p \in[0, \bar{p}]$ is followed by the distribution function $\Phi(p)$. If the worker is shirking, his/her productivity is followed by the distribution function $\Phi^{S}(\hat{p})$.

[4] The firm makes a decision regarding dismissal after revelation of productivity $p$. If an employee is fired, he/she receives severance pay (SP), is transferred to the unemployment pool, and gets the reservation wage $\bar{w}$. The firm firing the employee becomes a job vacancy in the labor market. On the other hand, if a worker retains employment in the firm, he/she produces output with the value $p$ and receives wage $w$.

[5] In the next period, the fired worker and the firm that dissolved the match search for a new job match in the labor market. On the other hand, the employee and the firm that maintain the match repeat the same process: the employee chooses whether or not to make an effort, and then the value of his/her productivity is stochastically determined. Each period's productivity is independent of the past.

\section{Employment protection}

When a firm fires an employee, the firm bears a firing cost $f$. After $p$ is revealed, the firm's current profit is $p-w$ if the firm maintains the match, or $-f$ if the firm fires the employee.

The firing cost $f$ borne by the firm consists of two factors: $f=s+z$, where (i) $s$ denotes monetary transfer such as severance pay (SP), and (ii) $z$ denotes procedural inconvenience (PI) such as administrative costs for notification and certification or negotiation with unions. PI is a socially wasteful transaction cost. SP is always given to all fired employees, including shirkers. SP and PI are social rules and are exogenously 
determined by the government.

\section{Matching technology}

The Mortensen-Pissarides-type matching function is given by $m=m(u, v)$, where $u$ is the unemployment rate, and $v$ is the number of vacant jobs as a fraction of the labor force, which is called the vacancy rate. The vacancy-unemployment ratio $v / u$ or $v-u$ ratio, indicating market tightness, is denoted as $\theta$. The matching function is assumed to be a constant return to scale, that is, $q(\theta) \equiv m\left(\frac{u}{v}, 1\right)$, where $q(\theta)$ denotes the probability with which a job vacancy will be matched to an unemployed worker. Clearly, $q^{\prime}(\theta) \leq 0$. Similarly, the probability with which the unemployed worker will be matched to a job vacancy is given by $\theta q(\theta)$.

In the labor market, all unemployed workers are considered identical regardless of their past behaviors, since their past behaviors are not noted in the market. Hence, the matching probability is equivalent among the unemployed. Similarly, all job vacancies in the market are identical for the unemployed.

\section{Incentive compatibility}

As we show later, an employee is fired in the case of $p \in[0, \hat{p})$, where the threshold $\hat{p}$ is endogenously determined. A diligent worker who made an effort is fired with the probability $\Phi(\hat{p})$. If a diligent worker is fired for low productivity, he/she receives SP from his/her firm and is transferred to the unemployment pool. His/her expected current payoff is given by $\Phi(\hat{p})(s+\bar{w})+(1-\Phi(\hat{p})) w-c$.

If an employee shirks, he/she is fired with the probability $\Phi^{S}(\hat{p})$. The expected current payoff of a shirking employee is $\Phi^{S}(\hat{p})(s+\bar{w})+\left(1-\Phi^{S}(\hat{p})\right) w$. Since the court cannot distinguish between a diligent employee and a shirking one, a firm has to pay SP even to a shirking employee.

The present-discounted value of the payoff of a diligent or shirking employee is denoted as $E^{N}$ or $E^{S}$, respectively. Since an employee can decide whether or not to make an effort, the present-discounted value of an employee is given by $E \equiv \max \left\{E^{N}, E^{S}\right\}$. We apply a discrete-time model, and thus the present-discounted value of a diligent employee's payoff is as follows:

$$
E^{N}=\Phi(\hat{p})(s+\bar{w})+(1-\Phi(\hat{p})) w-c+\frac{1}{1+r}\{\Phi(\hat{p}) U+(1-\Phi(\hat{p})) E\}
$$


where $r$ is the time preference rate and $U$ is the present-discounted value of the payoff to the unemployed. Similarly, the present-discounted value of a shirking employee's payoff is given by

$$
E^{S}=\Phi^{S}(\hat{p})(s+\bar{w})+\left(1-\Phi^{S}(\hat{p})\right) w+\frac{1}{1+r}\left\{\Phi^{S}(\hat{p}) U+\left(1-\Phi^{S}(\hat{p})\right) E\right\}
$$

Finally, the present-discounted value of the unemployed is as follows:

$$
U=\bar{w}+\frac{1}{1+r}\{\theta q(\theta) E+(1-\theta q(\theta)) U\}
$$

where the reservation wage for the unemployed $\bar{w}$ indicates the value of leisure.

The incentive compatibility (IC) and individual rationality (IR) are given by $E^{N} \geq E^{S}$ and $E \geq U$, respectively. The wage $w$ should be more than the reservation wage $\bar{w}$; otherwise, no worker would be willing to search for a new job. It holds from $w>\bar{w}$ that $E^{S}>U$, because an employee receives the higher wage $w$ or the reservation wage $\bar{w}$ with severance pay $s$. This means that $E \geq U$ always holds as long as $E^{N} \geq E^{S}$ holds. Therefore, it is sufficient to focus on the constraint $E^{N} \geq E^{S}$. The following condition is introduced on the basis of $E^{N} \geq E^{S}$ and $E \geq U$ :

$$
I C(w) \equiv\left(\frac{(r+\theta q(\theta)+1)(w-\bar{w})-(r+\theta q(\theta)) s}{r+\theta q(\theta)+\Phi^{S}(\hat{p})}\right)\left(\Phi^{S}(\hat{p})-\Phi(\hat{p})\right) \geq c
$$

If the constraint (4) is satisfied, the incentive compatibility (IC) and the individual rationality (IR) hold. Since the firm is willing to minimize the wage, $I C(w)$ is binding at the equilibrium.

\section{Dismissal}

Next, we consider the model from the perspective of the firm. The present-discounted value $J$ of a firm matched to a worker is as follows:

$$
J=-\Phi(\hat{p}) f+\int_{\hat{p}}^{\bar{p}}(p-w) \phi(p) d p+\frac{1}{1+r}\{\Phi(\hat{p}) V+(1-\Phi(\hat{p})) J\}
$$

The present-discounted value $V$ of a job vacancy is $V=-k+\frac{1}{1+r}\{q(\theta) J+(1-q(\theta)) V\}$, 
where $k$ is job vacancy cost. Since it holds that $V=0$ from the free entry and exit condition on job vacancies, we obtain $J=\frac{(1+r) k}{q(\theta)}$. Further, $\tilde{J}$ is defined as $\tilde{J} \equiv \frac{J}{1+r} ;$ thus

$$
\tilde{J}=\frac{1}{r+\Phi(\hat{p})}\left\{\int_{\hat{p}}^{\bar{p}}(p-w) \phi(p) d p-\Phi(\hat{p}) f\right\} \quad\left(=\frac{k}{q(\theta)}\right) .
$$

Here, the threshold of dismissal $\hat{p}$ is involved. If a firm fires an employee, the present-discounted profit is $-f$ given that $V=0$. On the other hand, if the firm maintains the match, it is given by $p-w+\frac{k}{q(\theta)}$. Hence, the threshold is given by

$$
\hat{p}=w-f-\frac{k}{q(\theta)}
$$

The threshold depends on the wage and the firing cost. A decrease in wage or increase in the firing cost reduces the threshold $\hat{p}$. Note that the threshold is given after the wage has been specified and the effort cost has been sunk. An employee and a firm can take the threshold $\hat{p}$ into account upon being matched. A firm, therefore, minimizes the wage subject to (4) and (6) from the backward induction consideration.

The threshold $\hat{p}$ must be positive for the employee's incentive: $\hat{p}>0$. If $\hat{p}=0$ holds, an employee is never fired, and thus the constraint (4) on incentives is never satisfied. The absence of the threat of dismissal motivates an employee to shirk. This is the common result in the efficiency wage model.

\section{Beveridge curve}

The constraint (4) on incentives, the present-discounted value of a firm's profit (5), and the threshold of dismissal given by (6) specify the search equilibrium $(\theta, w)$. The job creation rate is given by $\theta q(\theta) \frac{u}{1-u}$, and the job destruction rate is $\Phi(\hat{p})$. From the steady state condition in terms of job flow, the job creation rate should be equivalent to the job destruction rate, and thus the equilibrium unemployment rate is given by 


$$
u=\frac{\Phi(\hat{p})}{\Phi(\hat{p})+\theta q(\theta)}
$$

This is the Beveridge curve.

\section{Search equilibrium}

Although unstable equilibria can exist in our model, it is reasonable to focus on stable equilibria. It is assumed that adjustment of the entry or exit of job vacancies in the market is slower than the wage adjustment in a match. A firm is too small to influence market tightness $\theta$, and minimizes the wage given the market tightness subject to the constraint (4) on incentives. The constraint (4), therefore, is binding at all times, even if the economy is not at the search equilibrium. The locally stable condition of equilibria is given by

$$
I C_{w} \frac{k q^{\prime}}{q^{2}}-I C_{\theta} \tilde{J}_{w}<0
$$

where $I C_{w} \equiv \frac{\partial I C(w)}{\partial w}, I C_{\theta} \equiv \frac{\partial I C(w)}{\partial \theta}$, and $\tilde{J}_{w} \equiv \frac{\partial \tilde{J}}{\partial w}$.

The search equilibrium is represented by the point of intersection in Figure $1 .^{1}$ The wage is adjusted more smoothly than the entry or exit of job vacancies; therefore, the economy is almost always on the IC curve of the constraint (4). In Figure 1, point $A$ on $I C(w)=c$, which is near the equilibrium $E_{1}$, is below the JC curve of (5); hence, the expected profit of a job vacancy at point $A$ is positive, causing more job vacancies in the market. The economy will be distant from the equilibrium $E_{1}$; therefore, equilibrium $E_{1}$ is unstable, while, equilibrium $E_{2}$ is stable. Although we do not explicitly consider the transition dynamics, our focus is limited to the equilibrium satisfying the locally stable condition (8).

First, we consider how the change in the relative share of SP affects the economy given a constant level of firing cost, that is, $f=\bar{f}$.

\section{Proposition 1}

Suppose that the share of SP increases given a constant level $\bar{f}$ of the firing cost; the increase in the share of SP boosts the wage, the threshold of dismissal, and the

\footnotetext{
1 The IC curve, constraint (4), may be downward sloping or upward sloping. The slope of the IC curve is irrelevant to the result only if the stable condition (8) holds.
} 
unemployment rate. It also reduces the $v-u$ ratio.

The proof is provided in the appendix. When the stringency of EP is fixed, that is, $f=\bar{f}$, a firm incurs the same firing cost $f=\bar{f}$ regardless of the share of SP. Since a shirking employee is entitled to receive SP whenever he/she is fired, SP discourages an employee from putting in the required effort. A higher wage offer is therefore necessary to maintain the employee's incentives, which reduces the firm's profit from the match. This is the disincentive effect, which causes firms as vacancies to exit the market, thereby reducing market tightness.

Here, a graphical explanation (Figures 2a and 2b) enhances intuitive understanding. Since the total firing cost does not change, the JC curve of (5) does not shift. On the other hand, an increase in the share of SP shifts the IC curve of the constraint (4) upward, thereby increasing the wage and reducing market tightness (Figure 2a). Moreover, the job destruction rate depends on the threshold $\hat{p}$, which is pushed up by the increase in wage $w$ and the decrease in market tightness $\theta$. Therefore, the job destruction rate clearly increases, resulting in an increase in the unemployment rate from (7). The Beveridge curve (7) shifts due to the increase in the job destruction rate $\Phi(\hat{p})$ in Figure $2 \mathrm{~b}$. In addition, the JC curve in Figure $2 \mathrm{~b}$ turns clockwise because of the decrease in market tightness $\theta$. The increase in the share of SP, therefore, shifts the equilibrium from $E_{1}$ to $E_{2}$ (Figure $2 \mathrm{~b}$ ). Since the market tightness reduces, the unemployment rate increases unambiguously.

In contrast, if the share of PI increases, the wage reduces and market tightness increases. In addition, the threshold of dismissal and the unemployment rate decline.

\section{$\underline{\text { 3. Numerical Illustration }}$}

The results of Proposition 1 hold only when the total firing cost is fixed. The situation, however, is restrictive. In this chapter, we proceed from the limited case to a more general one. Unfortunately, the total effect is ambiguous from the theoretical perspective, so we conduct a computer simulation on the search equilibrium.

The equilibrium is characterized by the constraint (4) and the zero profit condition of a vacancy (5) along with the threshold (6). A base line situation is given in Table 1 . We consider the case in which productivity is uniquely distributed, that is, $\phi(p) \equiv \frac{1}{\bar{p}}=\frac{1}{100}$. Furthermore, the productivity density function of a shirking employee 
is given by $\phi^{S}(p)=\frac{1}{10}$ for $p \in[0,10]$ and $\phi^{S}(p)=0$ for $p \in[10,100]$. Although the distributions on the productivity of employees are quite simple, these distributions satisfy the first-order stochastic dominance. In the baseline situation, the unique search equilibrium exists.

\section{Wage and market tightness}

Figure 3 shows that the wage initially increases and then decreases with respect to $s$ (SP) given a level of $z(\mathrm{PI})$. This implies that an increase in SP damages the employee's incentives when SP is low. As a result, an increase in SP pushes the wage upward to maintain the employee incentives.

Figure 4 shows the relationship between market tightness and EP. An increase in SP decreases market tightness. This indicates that the present-discounted payoff $J$ of a matched firm is put down by the increase in SP, and hence job vacancies exit the labor market. The decline in market tightness is a credible threat to shirking behavior because fired workers have difficulty in obtaining reemployment. When SP is high, market tightness is very small, which results in a high cost of shirking behavior for employees. Therefore, as Figure 3 shows, the wage decreases after SP exceeds a particular level around $s=22$.

On the other hand, in Figure 3, the influence of PI on the wage is not significant when SP is low $(s \leq 19)$. When SP is in the middle range and PI is not very strict, for example, $s=25$ and $z=4$, the increase in PI lowers the incentive compatible wage. This indicates that the increase in PI positively affects the incentives of employees. Since PI deters a firm from firing employees frequently, a diligent employee benefits from the resultant high job security, and the lower wage is enough to maintain the incentive in exchange for high job security. This is the positive commitment effect. In Figure 4, an increase in PI also results in a decrease in market tightness when SP is either low or high. However, when SP is in the middle range, for example, around $s=$ 25, PI may increase the market tightness. However, if PI is excessively severe, in the case of $z=12$, for example, it reduces the market tightness.

\section{Threshold of dismissal and unemployment rate}

Figure 5 shows the effect of EP on the threshold $\hat{p}$ of dismissal. Figure 5 is similar to Figure 3. As SP increases, initially, an employee is more likely to be fired, and then is less likely to be fired. An increase in PI does not significantly affect the threshold of dismissal when SP is low. However, an increase of PI reduces the threshold 
as SP increases.

The relationship between the unemployment rate and EP is shown in Figure 6 . From (7), the unemployment rate depends on the market tightness and the threshold of dismissal. Since an increase in SP decreases the market tightness, as Figure 4 shows, the unemployment rate increases when SP increases the threshold of dismissal. As Figure 6 shows, the unemployment rate is increased by an increase in SP when SP is low. On the other hand, when SP is in the middle range, the threshold of dismissal reduces as SP increases. If this result dominates the reducing effect of market tightness, the unemployment rate decreases with respect to SP. In fact, around $s=25$ and $z=2$ or $z=$ 4 , the increase in SP reduces the unemployment rate.

When SP is in the middle range, Figure 4 and 5 indicate that, as PI increases, market tightness improves and the threshold of dismissal falls, resulting in a reduction in the unemployment rate. The effect of PI to reduce the unemployment rate appears when PI is in the appropriate range. If PI is severe, for example, $z=12$, the effect disappears; that is, an increase in severe PI causes an increase in the unemployment rate. However, when SP is low or high, the influence of PI on the unemployment rate is comparatively small.

\section{Welfare}

As the same situation is repeated in every period on the equilibrium path, it is sufficient to consider the welfare level in one period. Welfare in one period is given by

$$
\Omega \equiv\left\{\int_{\hat{p}}^{\bar{p}} p \phi(p) d p+\Phi(\hat{p})(\bar{w}-z)-c\right\}(1-u)+u \bar{w}-k \theta u
$$

Figure 7 shows the level of welfare. When SP is in the middle range, an appropriate PI improves welfare through the positive commitment effect.

In Figure 7, welfare improves gradually with respect to SP when SP is low. Although the effect of SP seems to be positive, this positive effect on welfare may be due to the elimination of the negative search externality. Naturally, welfare improves if EP solves the search externality.

Fortunately, we can infer the effect of the search externality on the basis of previous studies. When the bargaining power of an employee is weak compared to the elasticity of the matching function, as the Hosios (1990) condition shows, the unemployment rate is excessively low from the viewpoint of efficiency. In this case, welfare improves if a policy or an institutional device increases the unemployment rate. 
In our model, the level of SP is relevant to the bargaining power of an employee since high SP increases the ex post rent $E-U$ of an employee. High SP is relevant to the case in which an employee has strong bargaining power in the textbook model. This implies that welfare increases with respect to SP when SP is low. In fact, as Figure 7 shows, welfare improves as SP increases. The effect of improving welfare is attributed in part to the elimination of the negative search externality.

In the textbook Pissarides (2000) model, the efficient level of bargaining power is uniquely determined by the Hosios condition. When the bargaining power of an employee begins from a very low level, as the bargaining power increases, welfare improves initially and then declines. If the search externality was crucial to welfare in our model, the welfare curve should be shaped like a mound with respect to SP. In contrast, in our model, the welfare curve is not shaped like a mound, but is comparatively complex as shown in Figure 7. Thus, the result that PI improves welfare in the middle range of SP is not caused by the effect of eliminating the search externality.

\section{Long-term shock}

The discount rate in this numerical illustration is 0.0125 , which indicates that the model uses quarterly periods. Even if the productivity of an employee is low, he/she is unlikely to be fired if that situation continues only for a quarter. Taking the vacancy cost into account, a firm is willing to retain the employee if the low productivity is expected for only a short period. In contrast, if the low productivity persists for a long time, the firm would be unwilling to retain the match, and thus is likely to be dissolved.

To check the long-term low productivity situation, we implement a numerical illustration with a higher discount rate. For example, consider the case of $r=0.1$, which indicates that the low productivity situation continues for approximately 2 to 4 years. A high discount rate naturally increases the threshold of dismissal as well as the unemployment rate. However, in the middle range of SP, a more stringent PI, $z=8$, reduces the unemployment rate in the case of $r=0.1$ to a greater extent than in the case of $r=0.0125$. The difference in the unemployment rate between $z=8$ and $z=4$ is denoted as $\Delta u \equiv u_{z=8}-u_{z=4}$ in Figure 8a. To reduce the unemployment rate, PI is more effective in the case of $r=0.1$ than in the case of $r=0.0125$.

Similarly, the difference in welfare $\Delta \Omega \equiv \Omega_{z=8}-\Omega_{z=4}$ is represented in Figure $8 \mathrm{~b}$. The welfare-improving effect is larger in the case of $r=0.1$ than in the case of $r=$ 0.0125 . Thus, the positive effect of PI is not necessarily smaller when low productivity persists for a long time. 


\section{$\underline{\text { 4. Discussion and Conclusion }}$}

We examined the efficiency wage model with matching technology to analyze the effects of EP on worker incentives. EP generates two effects: the disincentive effect and commitment effect. If the latter dominates the former, EP improves welfare. We also examined the differences between SP and PI, finding that SP seems better than PI from the perspective of social welfare. However, SP is an earning for shirking employees, and thus it may negatively affect employee incentives as compared with PI.

Similar to the results of previous studies regarding EP, our results on the effects of EP were theoretically ambiguous. Therefore, we conducted a computer simulation, and the following results were obtained. [1] When SP is low or high, the disincentive effect dominates the commitment effect. In contrast, SP does not negatively affect the employee incentives when SP is in the middle range. [2] PI does not provide a sufficient effect to the economy when SP is low or high; however, it decreases the threshold of dismissal and the unemployment rate, and thus improves social welfare when SP is in the middle range. [3] Very stringent PI negatively affects the employee incentive. Therefore, it is necessary to design EP appropriately.

EP's negative disincentive effect is often noted, but its positive commitment effect deserves more attention. Supported by the incomplete contract theory, institutions act as commitment devices under contractual incompleteness. In fact, there are numerous studies on commitment devices, such as the financial debt theories of Aghion and Bolton (1992) and Dewatripont and Tirole (1994); the firm split-up model of Cremer (1995); the model on delegation of authority of Aghion and Tirole (1997); and the privatization model of Dewatripont and Maskin (1995), Schmidt (1996), and Qian and $\mathrm{Xu}$ (1998). Some studies show that unions function as commitment devices: Booth and Chatterji (1998) show that unions' bargaining power enhances skill formation and improves social welfare; Eguchi (2002) also points out the significance of unions as commitment devices for job security. In this paper, it has been shown that EP, especially PI, improves the economy through the commitment effect when workers' moral hazard is a serious problem.

We have not considered workers' bargaining power explicitly in this paper, but our model is relevant to the situation where the employees' bargaining power is weak. Rocheteau (2001) focuses on incentives and the bargaining power of employees, concluding that a firm inflexibly sets the wage, akin to the efficiency wage model, when 
the employees' bargaining power is weak. If the employees' bargaining power is strong, the wage and the threshold of dismissal are determined through the labor-management negotiations. According to our assumption, firms control the wage and the threshold of dismissal in our model, which therefore applies to the case of employees with weak bargaining power.

We considered the case in which the wage is decided flexibly during the formation of employment contracts but is inflexible ex post. Empirically, the issue of the degree of wage flexibility has been controversial. The differences in the views on macroeconomic policy often stem from differing views on the extent to which wage adjustment is performed flexibly. As Pissarides (2008) indicates, the wage of a new match relevant to the external wage of outsiders is comparatively flexible, but the continuous wage of an existing match is comparatively inflexible, thereby making the setting of the model consistent with the real world.

Other studies, however, support the reasonableness of our assumption. Bewley (1999) conducted interviews with over 200 business people, including firm managers, lawyers, and consultants; Campbell and Kamlani (1997) conducted investigations on firm managers. These studies suggest that wages are inflexible for the reason why wage cut gives serious damages to motivation. Furthermore, according to behavioral science, there are some psychological factors that deter firm managers from decreasing wages. A well-known psychological effect-the money illusion-makes wage declines less preferable than increases. Kahneman, Knetsch, and Thaler (1986) and Agell and Bennmarker (2007) report that workers tend to prefer constant nominal wages with inflation over nominal wage decline without inflation, even if both result in identical amounts of real wages. In addition to these studies, there are experimental studies such as Fehr and Falk (1999) that show wages to be inflexible in the case of excessive labor supply and involuntary unemployment. The experimental studies indicate that firm managers experience difficulty in downward wage adjustment.

Recently, the relationship between wage rigidity and the matching model has been a widely discussed issue. Shimer (2005) indicates that the Mortensen-Pissarides matching model can hardly explain the volatility of unemployment and vacancies, and Hall (2005) shows that introducing wage rigidity in the model improves its suitability. While Mortensen and Nagypal (2007) and Pissarides (2009) mention that wage rigidity improves the model's power of explanation; they argue that the model does not require wage rigidity. According to them, the power of explanation improves if other factors such as hiring or firing costs, demand shocks, and on-the-job search behavior are considered in the typical model. In addition, as Kennan (2010), Moen and Roser (2007), 
and Brugemann and Moscarini (2007) analyze the issue, asymmetric information like adverse selection and moral hazard magnify the volatility in unemployment and vacancies. Although this controversial topic of volatility is crucial, it is beyond the scope of this paper.

In this paper, we have focused on the effects of EP without taking unemployment insurance (UI) into consideration; however, we recognize that it is crucial to compare EP with UI. In fact, there are seminal studies on the comparison between EP and UI. Ljungqvist and Sargent (1998) (2007) and Rogerson and Schindler (2002) reveal that UI prevents the unemployed from obtaining a new job, and thus leads to long-term unemployment. ${ }^{2}$ Pissarides (2001) shows that there is no scope for improving welfare by implementing EP if UI is perfect; however, EP has positive effects on welfare if UI is imperfect. Blanchard and Tirole (2008) indicate that an appropriate mixture of dismissal tax as EP and UI is necessary because of the imperfectness of UI, liquidity constraints, or wage bargaining. Mortensen and Pissarides (1999) focus on different effects between skilled and unskilled workers. They show that UI affects the job-search incentives of unskilled workers more negatively than those of skilled workers, and that EP increases job security more for the skilled than for the unskilled.

Thus, while we realize that UI is an important topic when considering employment problems, we have not included it in our paper. This is because, in our paper, a risk problem is not crucial since we assume the players to be risk neutral. In addition, full insurance is not incentive compatible in the case of moral hazard. Our main message is that EP positively affects employee incentives if it is appropriately designed. In fact, even if we assume that UI is included in the reservation wage, the introduction of UI is irrelevant to our results. Of course, we acknowledge that a precise analysis should be done, but that will be dealt in a future study.

\section{$\underline{\text { Appendix }}$}

\section{Proof of Proposition 1}

Since the constraint (4) is binding at the equilibrium, at the equilibrium

\footnotetext{
${ }^{2}$ In contrast, Acemoglu and Shimer (1999) note that UI enables the unemployed to carefully search for a new job that corresponds exactly to their characteristics.
} 
$I C_{w} \equiv \frac{\partial I C(w)}{\partial w}>0$ holds. The proof is as follows. Suppose that $I C_{w} \leq 0$. In this situation, the firm can reduce the wage further as long as the constraint (4) is satisfied, and thus increase the firm's profit. This contradicts the notion that the original wage maximizes the firm's profit. Hence, at the equilibrium $I C_{w}>0$ holds.

Next, we conduct comparative statics on the search equilibrium with respect to $s$ subject to $d f=d s+d z=0$ as follows:

$$
\left(\begin{array}{l}
d w / d s \\
d \theta / d s
\end{array}\right)=\frac{-1}{I C_{w} \frac{k q^{\prime}}{q^{2}}-I C_{\theta} \tilde{J}_{w}}\left(\begin{array}{cc}
\frac{k q^{\prime}}{q^{2}} & -I C_{\theta} \\
-\tilde{J}_{w} & I C_{w}
\end{array}\right)\left(\begin{array}{c}
I C_{s} \\
\tilde{J}_{s}
\end{array}\right),
$$

where $\quad I C_{s} \equiv \frac{\partial I C(w)}{\partial s}=-\frac{r+\theta q(\theta)}{r+\theta q(\theta)+\Phi^{S}(\hat{p})}\left\{\Phi^{S}(\hat{p})-\Phi(\hat{p})\right\}<0 \quad$ and $\quad \tilde{J}_{s} \equiv \frac{\partial \tilde{J}}{\partial s}=0$ Using the locally stable condition (8) and $\tilde{J}_{w}=-\frac{1-\Phi(\hat{p})}{r+\Phi(\hat{p})}<0$,

$$
\left(\begin{array}{l}
d w / d s \\
d \theta / d s
\end{array}\right)=\frac{-1}{I C_{w} \frac{k q^{\prime}}{q^{2}}-I C_{\theta} \tilde{J}_{w}}\left(\begin{array}{c}
\frac{k q^{\prime}}{q^{2}} I C_{s} \\
-\tilde{J}_{w} I C_{s}
\end{array}\right) \text { holds. }
$$

Hence, $\left.\frac{d w}{d s}\right|_{f=\bar{f}}>0$ and $\left.\frac{d \theta}{d s}\right|_{f=\bar{f}}<0$. The results lead to $\left.\frac{d \hat{p}}{d s}\right|_{f=\bar{f}}>0$ from (6), and thus, it holds from (7) that $\left.\frac{d u}{d s}\right|_{f=\bar{f}}>0$ 


\section{$\underline{\text { References }}$}

Acemoglu, Daron, and Robert Shimer (1999) "Efficient Unemployment Insurance," Journal of Political Economy vol.107, 893-928.

Agihon, Philippe, and Patrick Bolton (1992) “An Incomplete Contracts Approach to Financial Contracting," Review of Economic Studies vol. 59, 473-494.

Agihon, Philippe, and Jean Tirole (1997) "Formal and Real Authority in Organizations," Journal of Political Economy vol. 105, 1-29.

Agell, Jonas, and Helge Bennmarker (2007) "Wage Incentives and Wage Rigidity:

A Representative View from Within," Labour Economics vol. 14, 347-369.

Bewely, Truman F. (1999) "Why Wages don't Fall during a recession," Harvard University Press, Cambridge, MA.

Blanchard, Olivier, and Jean Tirole (2008) "The Joint Design of Unemployment Insurance and Employment Production: A First Pass," Journal of the European Economic Association vol. 6, 45-77.

Booth, Alison, and Monojit Chatterji (1998) "Unions and Efficient Bargaining," Economic Journal vol.108, 328-343

Brugemann, Bjorn, and Giuseppe Moscarini (2007) "Rent Rigidity, Asymmetric Information, and Volatility Bounds in Labor Markets," Yale University, mimeo. (NBER Working Paper 13030)

Campbell 3ed, Carl M., and Kunal S. Kamlani (1997) “The Reasons for Wage Rigidity: Evidence from a Survey of Firms," Quarterly Journal of Economics vol. $112,759-789$.

Cremer, Jacques (1995) “Arm’s Length Relationships,” Quarterly Journal of Economics vol. 110, 275-295.

Dewatripont, Mathias, and Eric Maskin (1995) "Credit and Efficiency in Centralized and Decentralized Economies," Review of Economic Studies vol. 62, 541-555.

Dewatripont, Mathias, and Jean Tirole (1994) "A Theory of Debt and Equity:

Diversity of Securities and Manager-Shareholder Congruence,"

Quarterly Journal of Economics vol. 109, 1027-1054.

Eguchi, Kyota (2002) "Unions as Commitment Devices," Journal of Economic Behavior and Organization vol. 47, 407-421.

Fehr, Ernst, and Armin Falk (1999) "Wage Rigidity in a Competitive Incomplete Contract Market," Journal of Political Economy vol. 107, 106-134.

Fella, Giulio (2000) "Efficiency Wage and Efficient Redundancy Pay," European Economic Review vol. 44, 1473-1490. 
Galdon-Sanchez, Jose E., and Maia Guell (2003) "Dismissal Conflicts and Unemployment," European Economic Review vol. 47, 323-335.

Hall, Robert (2005) "Employment Fluctuations with Equilibrium Wage Stickiness," American economic review, vol. 95, 50-65.

Hosios, Arthur J. (1990) "On the Efficiency of Matching and Related Models of Search and Unemployment," Review of Economic Studies, vol. 57, 279-298.

Kahneman, Daniel, Jack L. Knetsch, and Richard Thaler (1986) "Fairness as a Constraint on Profit Seeking: Entitlements in the Market," American Economic Review vol. 76, 728-741.

Kennan, John (2010) "Private Information, Wage Bargaining and Employment Fluctuations," Review of Economic Studies, vol. 77, 633-664.

Ljungqvist, Lars, and Thomas Sargent (1998) "The European Unemployment Dilemma," Journal of Political Economy vol. 106, 514-550.

Ljungqvist, Lars, and Thomas Sargent (2007) "Understanding European Unemployment with Matching and Search-island Models," Journal of Monetary Economics, vol. 54, 2139-2170.

Moen, Espen R. and Asa Roser (2007) "Incentives in Competitive Search Equilibrium," mimeo.

Mortensen, Dale T., and Christopher A. Pissarides (1999) "Unemployment Responses to 'Skill-Biased' Technology Shocks: The Role of Labour Market Policy," Economic Journal, vol. 109, 242-265.

Mortensen, Dale, T. and Eva Nagypal (2007) "More on Unemployment and Vacancy Fluctuations," Review of Economic Dynamics, vol. 10, 327-347.

Pissarides, Christopher A. (2000) "Equilibrium Unemployment Theory," MIT Press.

Pissarides, Christopher A. (2001) "Employment Protection," Labour Economics, vol. 8, 131-159.

Pissarides, Christopher A. (2009) "The Unemployment Volatility Puzzle: Is Wage Stickiness the Answer?" Econometrica, vol.77, 1339 - 1369.

Qian, Yingy, and Chenggang Xu (1998) "Innovation and Bureaucracy under Soft and Hard Budget Constraints," Review of Economic Studies, vol. 65, 151-164.

Rogerson, Richard, and Martin Schindler (2002) "The Welfare Costs of Worker Displacement," Journal of Monetary Economics, vol. 49, 1213-1234.

Rocheteau, Guillaume (2001) "Equilibrium Unemployment and Wage Formation with Matching Friction and Worker Moral Hazard," Labour Economics, vol. 8, 75-102.

Shapiro, Carl, and Joseph Stiglitz (1984) “Equilibrium Unemployment as 
a Discipline Device," American Economic Review, vol. 74, 433-444.

Shimer, Robert (2005) "The cyclical behavior of equilibrium unemployment and Vacancies," American Economic Review, vol. 95, 25-49.

Schmidt, Klaus M. (1996) "The Costs and Benefits of privatization," Journal of Law, Economics, and Organization, vol. 12, 1-24. 


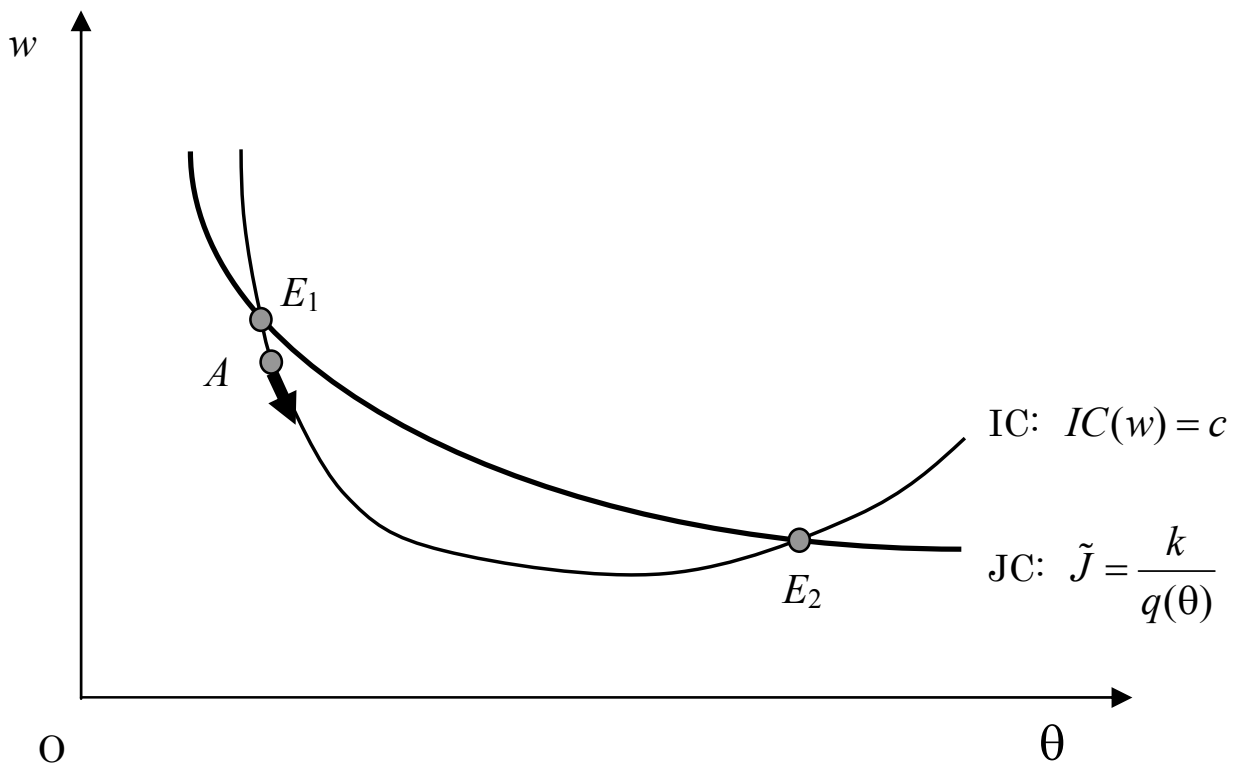

Figure 1

The equilibrium $E_{1}$ is unstable, but $E_{2}$ is stable. 


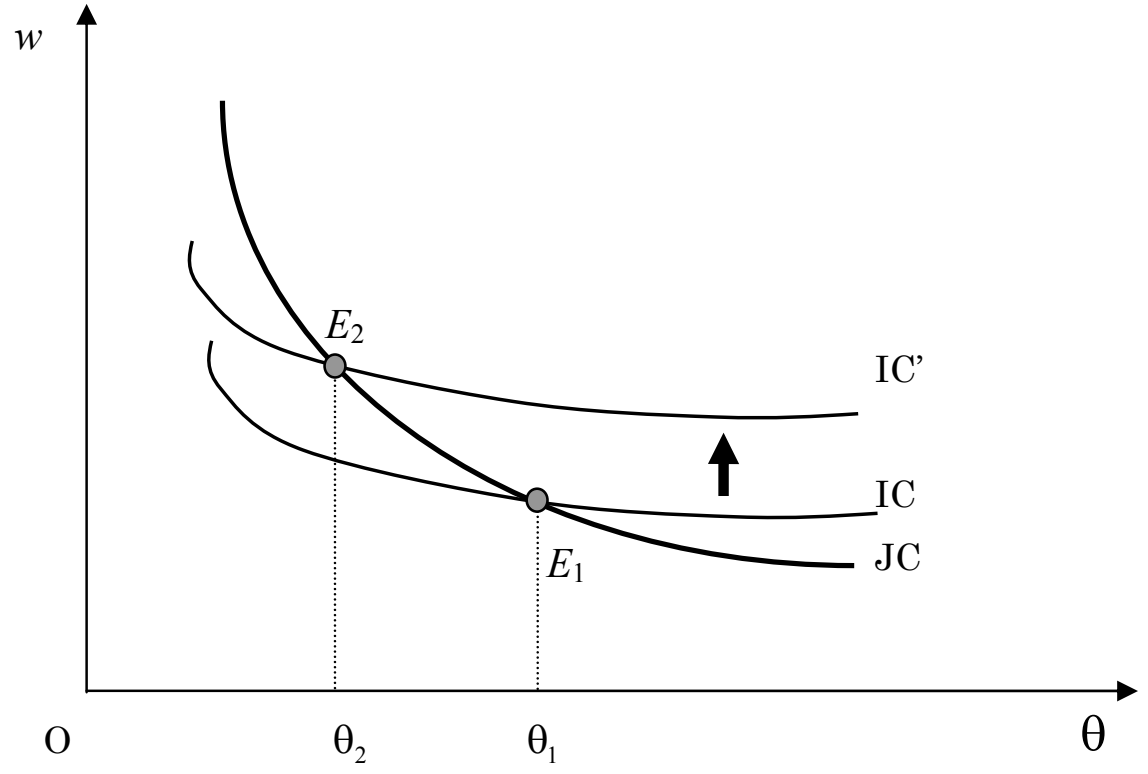

Figure 2a

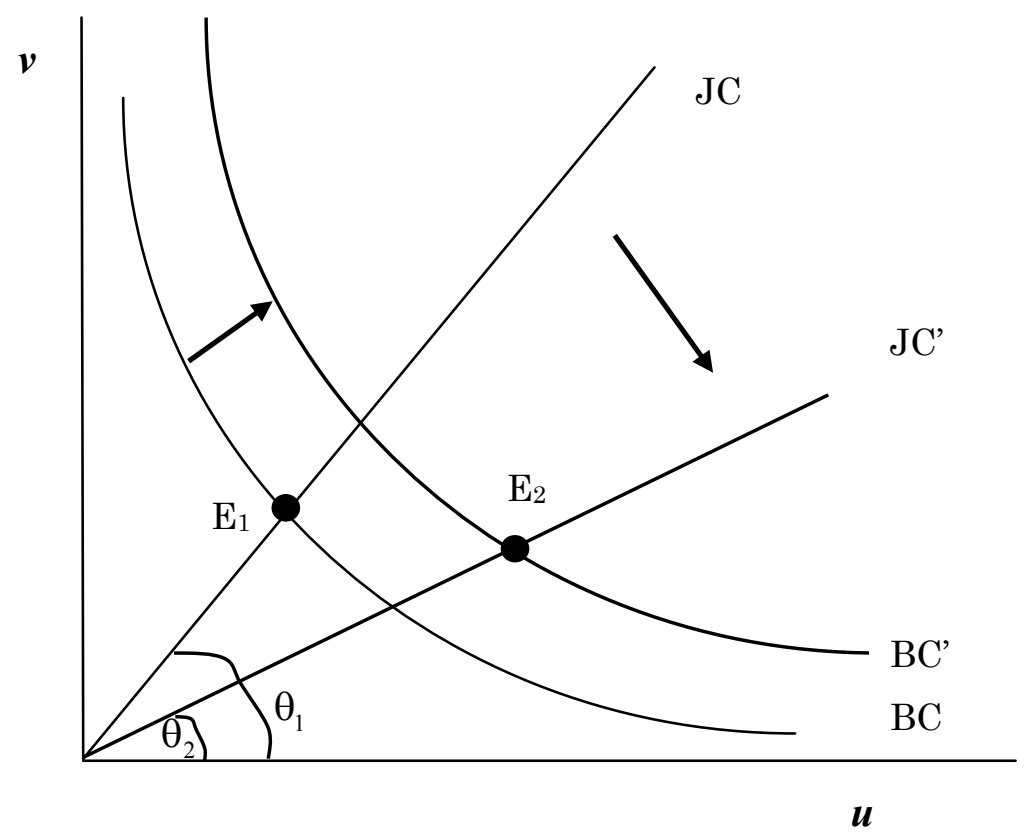

Figure 2b 


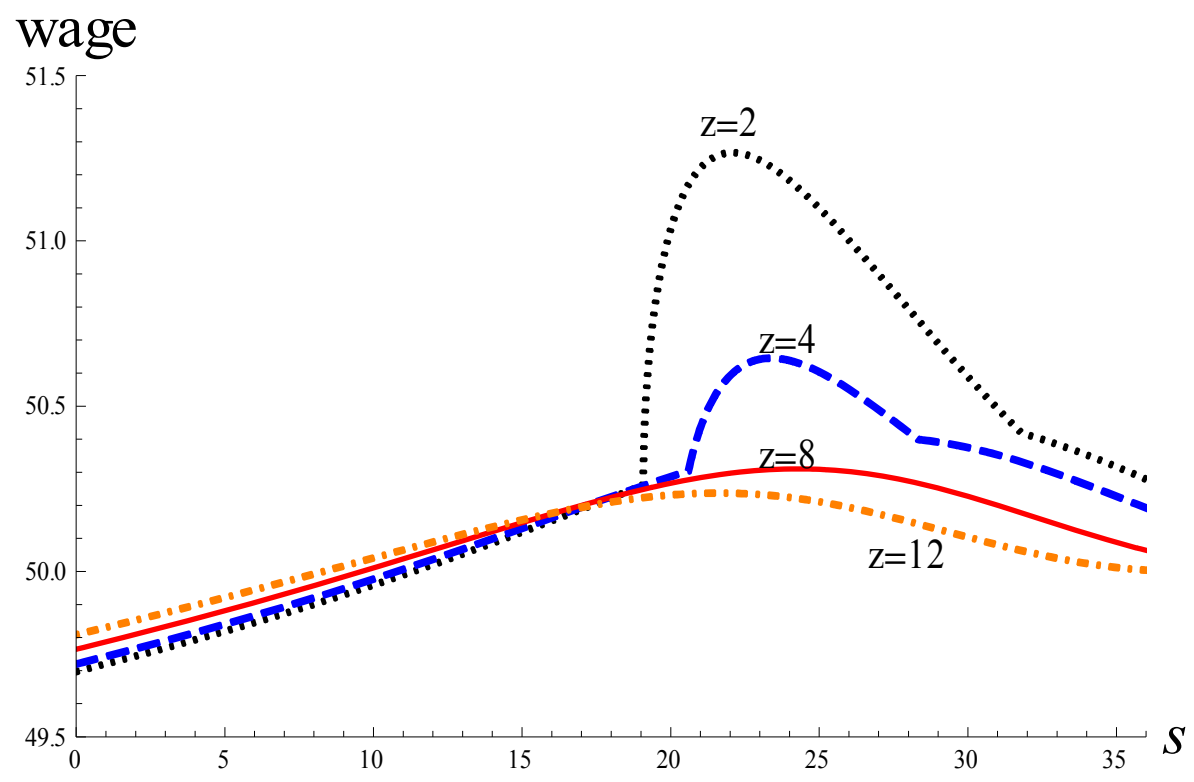

Figure 3: Wages 


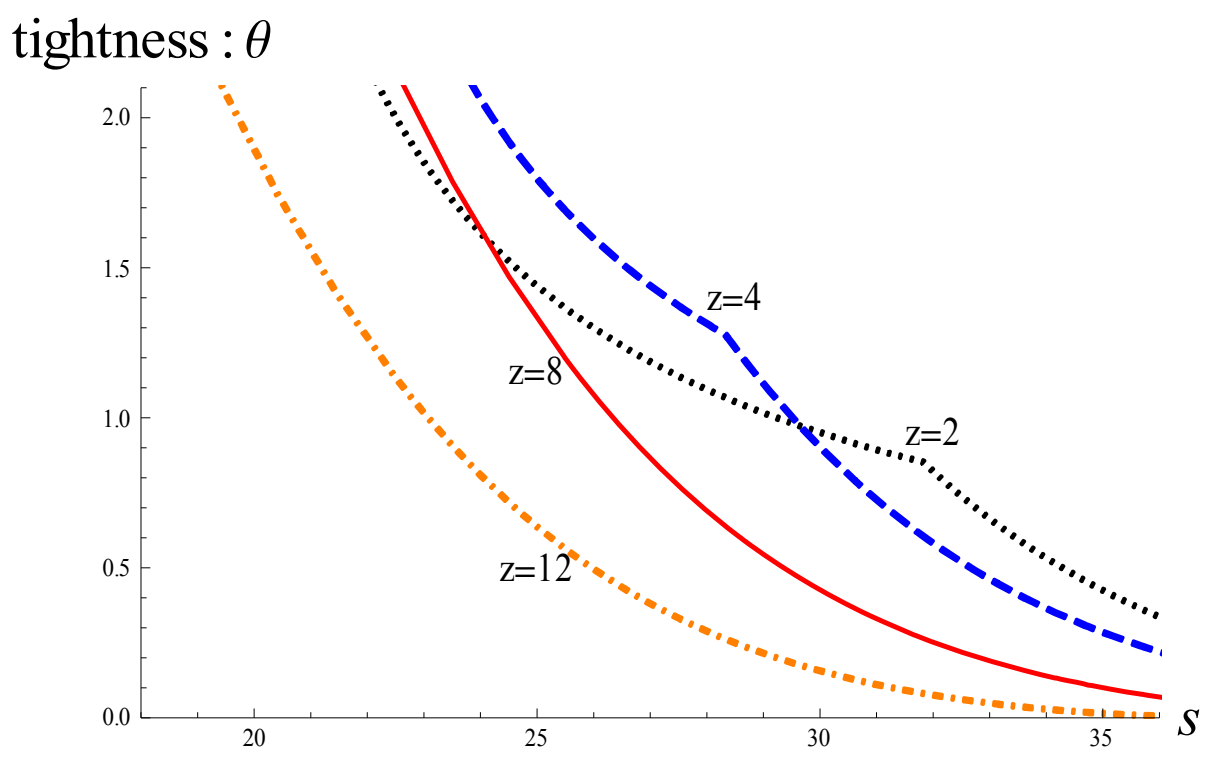

$\underline{\text { Figure 4: Market Tightness }}$ 
threshold : $\hat{p}$

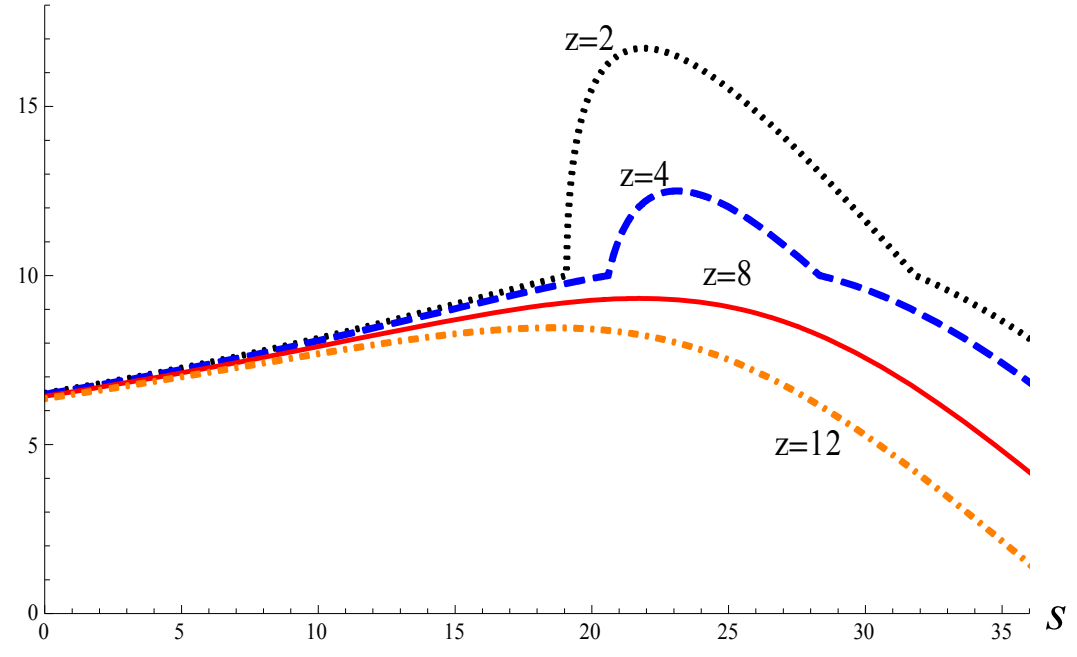

Figure 5: The Threshold 


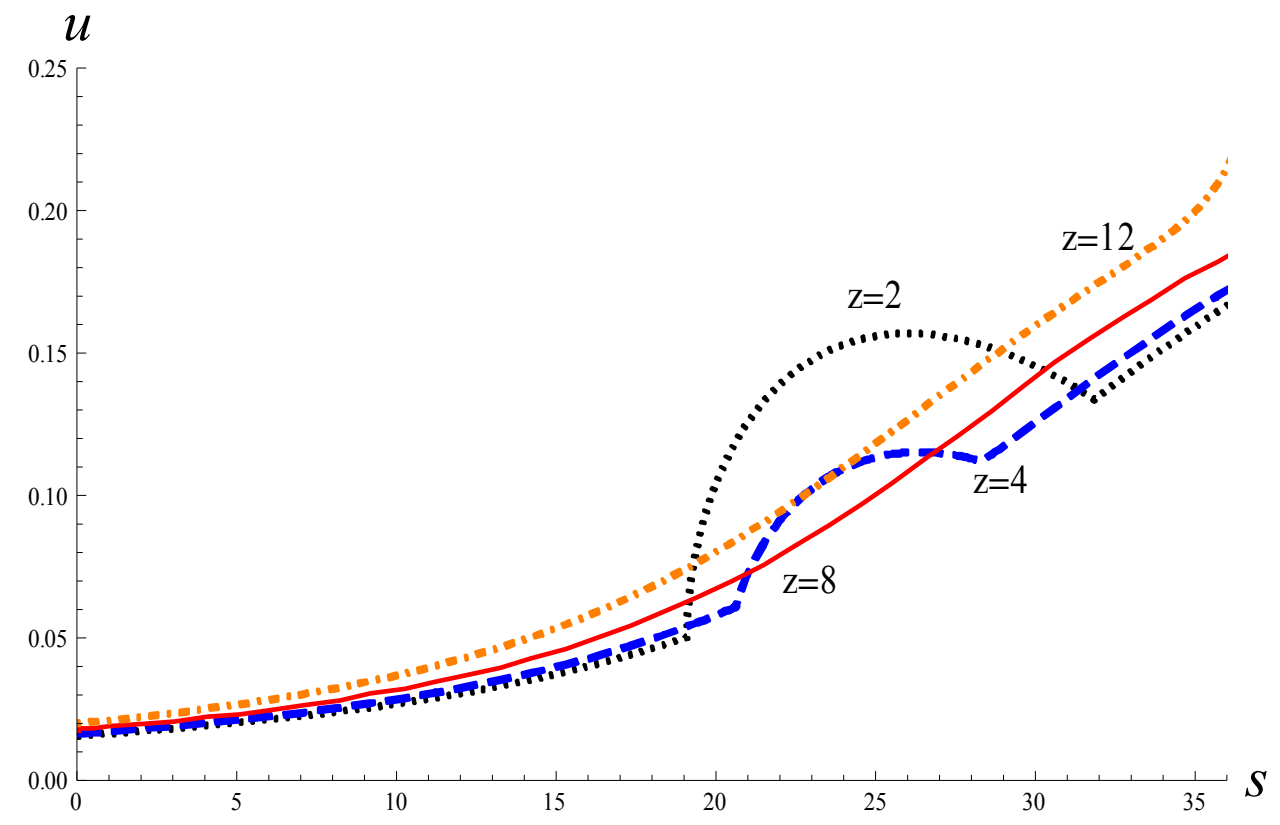

Figure 6: Unemployment Rate 


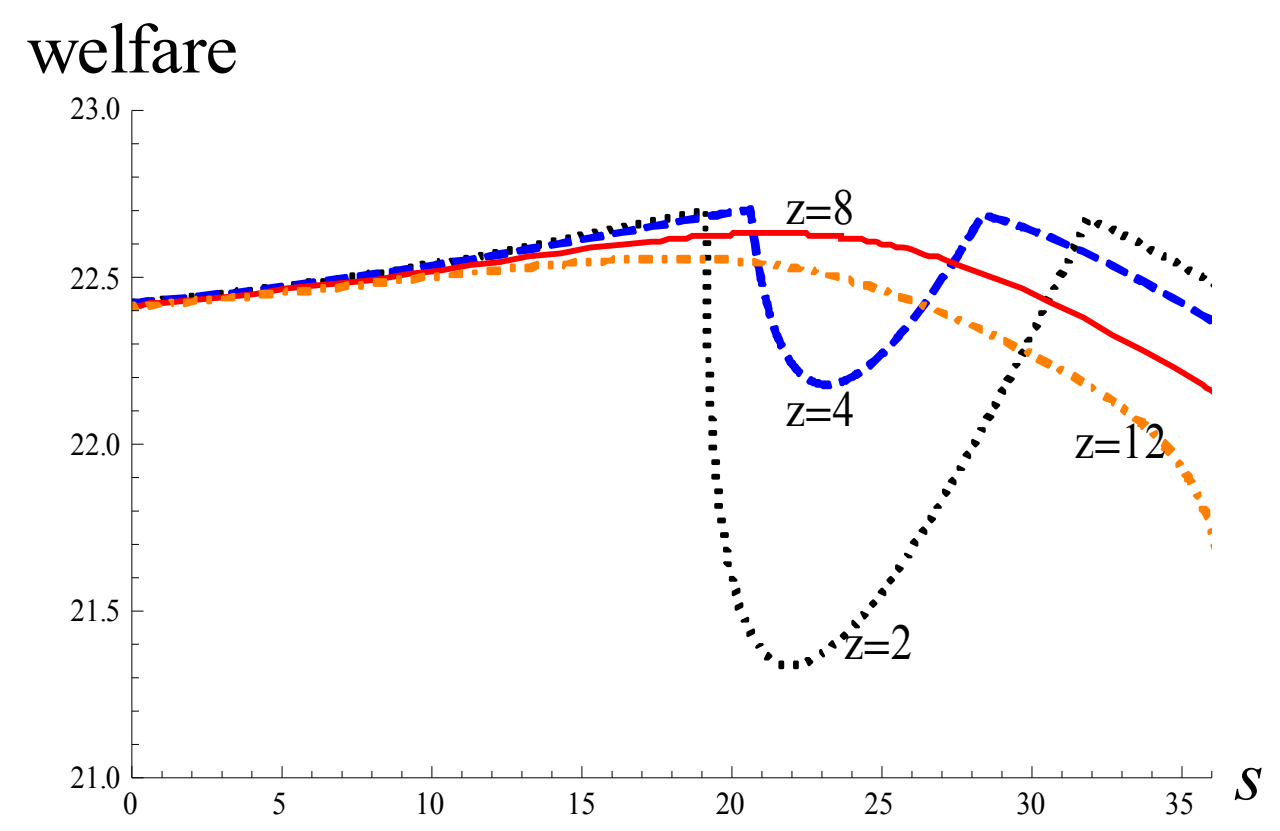

Figure 7: Welfare 


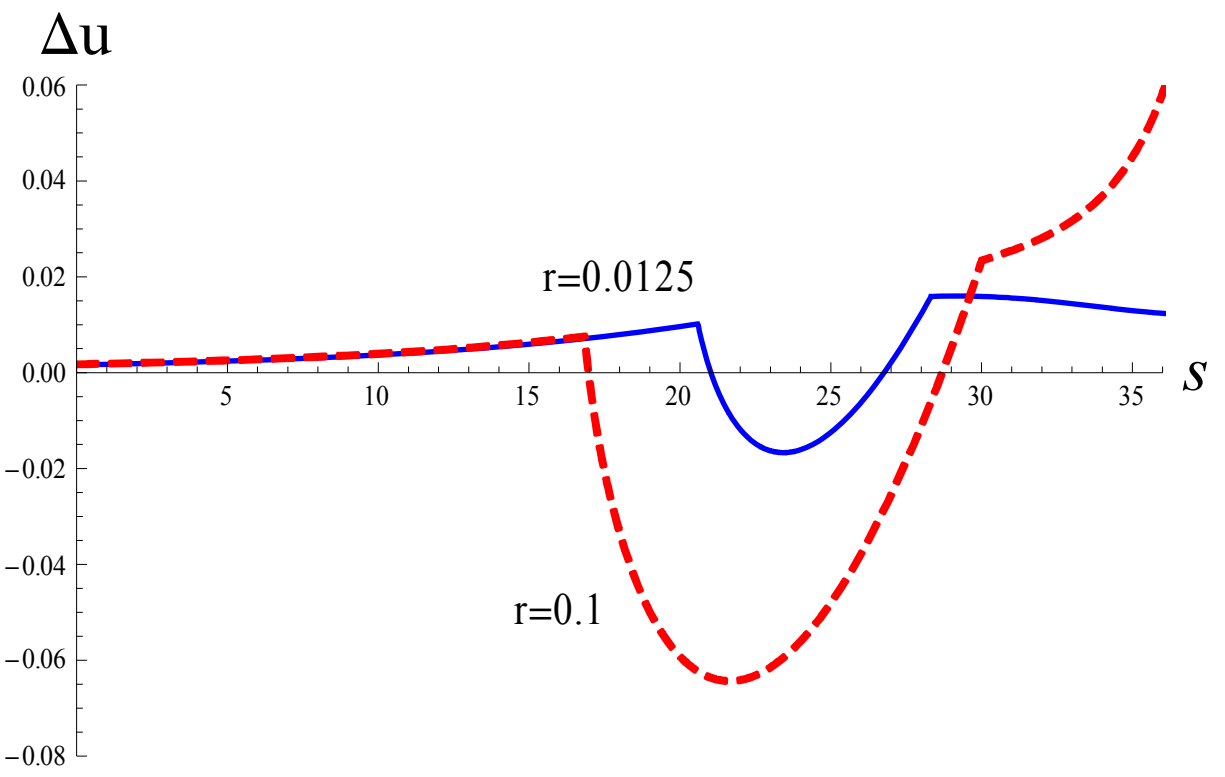

$\underline{\text { Figure 8a }}$

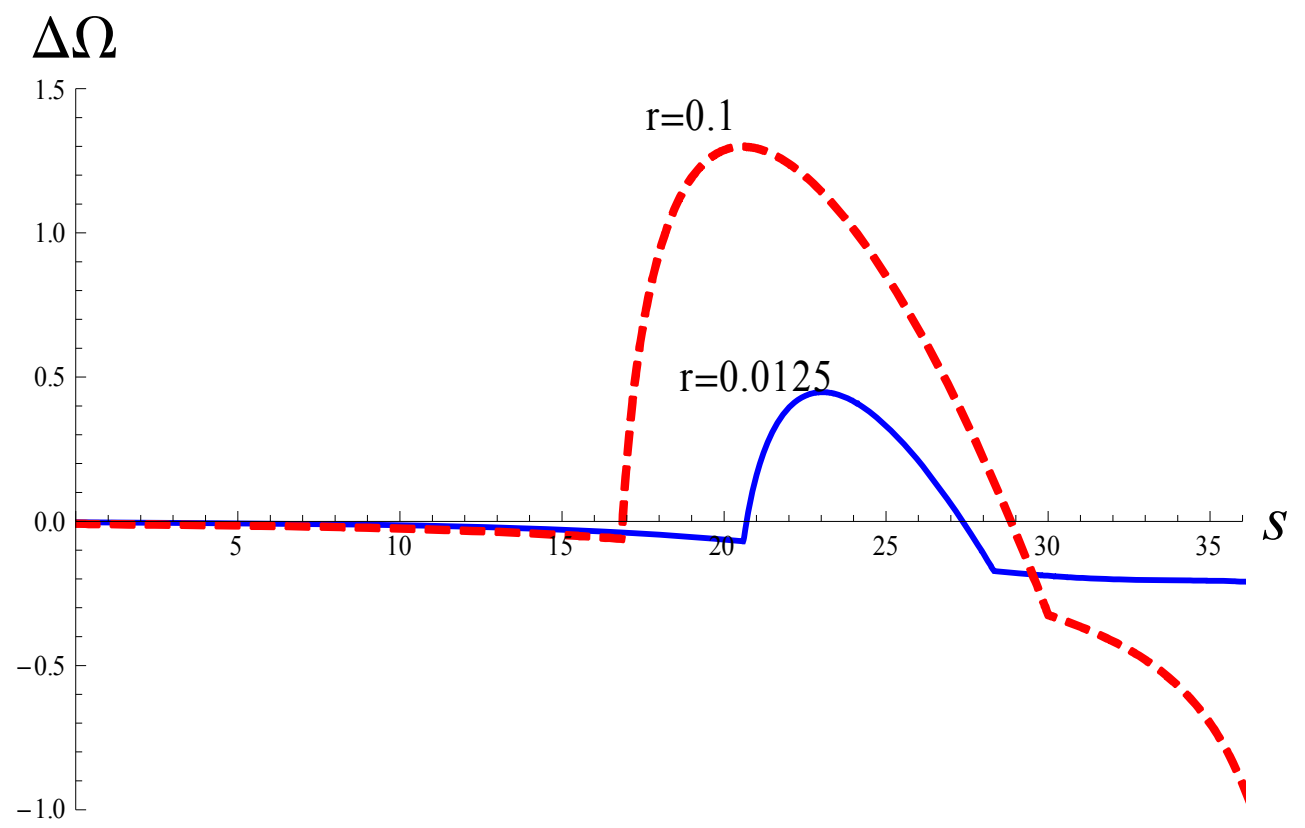

$\underline{\text { Figure } 8 \mathrm{~b}}$ 
Table 1

Values of Parameters

\begin{tabular}{|l|l|}
\hline Parameters & Values \\
\hline range of state & $p \in[0,100]$ \\
\hline $\begin{array}{l}\text { density function of diligent } \\
\text { workers }\end{array}$ & $\phi(p)=\frac{1}{100}$ for $p \in[0,100]$ \\
\hline $\begin{array}{l}\text { density function of shirking } \\
\text { workers }\end{array}$ & $\phi^{S}(p)=\left\{\begin{array}{cc}\frac{1}{10} & \text { for } p \in[0,10] \\
0 & \text { for } p \in[10,100]\end{array}\right.$ \\
\hline reservation wage & $\bar{w}=10$ \\
\hline interest rate & $r=0.0125$ \\
\hline effort cost & $c=25$ \\
\hline vacancy cost & $k=5$ \\
\hline matching function & $m=0.7(u v)^{0.5}$ \\
\hline
\end{tabular}

